\title{
E-LEARNING UTILIZATION AND THE IMPACT FOR PEOPLE DEVELOPMENT IN RETAIL COMPANY
}

\author{
Wahyu SARDJONO ${ }^{1}$, Maryani MARYANI ${ }^{2}$, Jajat SUDRAJAT ${ }^{3}$, and Astari RETNOWARDHANI ${ }^{4}$ \\ ${ }^{1,4}$ Information Systems Management, Binus Graduate Program, Bina Nusantara University, Jakarta Barat, INDONESIA \\ ${ }^{2}$ Information Systems Department, School of Information Systems, Bina Nusantara University, Jakarta Barat, INDONESIA \\ ${ }^{3}$ BINUS Entrepreneurship Center, Management Department, BINUS Business School Undergraduate Program \\ Bina Nusantara University, Jakarta Barat, INDONESIA \\ 1'wahyu.s@binus.ac.id, ${ }^{2}$ yanie@binus.edu, ${ }^{3}$ jsudrajat@binus.edu, ${ }^{4}$ aretnowardhani@binus.edu
}

\begin{abstract}
Industrial 4.0 has created changes in so many aspects of human life which require people not only to master their field of expertise but also to keep themselves at par with the latest trend and technology. Changes that happen rapidly, creating a volatile and complex condition with high level of uncertainty and ambiguity, which known as VUCA era. This state forcing workforces to be able to adapt in fast pace. E-learning which combines the traditional teaching process with the use of technology such as internet, Learning Management System (LMS) considered as the appropriate method to be implemented in order to meet all the challenges and requirements of industry 4.0. In retail industry, PT XYZ. and its subsidiaries have been utilizing Learning Management System (LMS), MOOC (Massive Open Online Courses), and virtual classes as part of the development program given to the employees. The main goal is to ensure that the employees as their most important asset will be able to keep themselves updated to the latest trend, topic and communication from the company. While the intention of this article is to see how the impact of E-Learning for people development is in this Industry 4.0 era, particularly in Indonesia's largest lifestyle retail company.
\end{abstract}

Keyword: Industry 4.0, VUCA, E-Learning, Learning Management System, people development, e-learning, MOOC

\section{BACKGROUND}

Currently the world is in the stage of the fourth industrial era, in which technological advances have led to major upheavals in all activities in human life. The bold characteristic of the era is the increased connectivity, human interaction, and the development of digital systems, artificial intelligence (AI) and virtual things. With the increase of convergent boundaries between humans, mechanical machineries and other resources, information and communication technology have certainly impacting various aspects including the learning process.

Technology has also push changes to happen rapidly that require every people and every business to be able to cope up and ensure that they are able to stay in the league. PT XYZ. (MAP) as Indonesia's largest lifestyle retailer, has been introducing e-learning to the employees as of 2014. MAP has the license for more than 120 well known international brands and recorded for more than 2,000 stores by end of 2020. Zara, Starbucks, Planet Sports, Reebok, Marks \& Spencer, and Burger King are to name a few brands managed by the company. With the business expansions to different region in Indonesia as well as to neighboring countries, the demand for fast and real time information and learning content dissemination is increasing exponentially. The company needs to seek the most appropriate ways to deliver development program effectively to the employees. E-learning considered as the best solution as it combines technology into the learning process, conveyed through telecommunication system and information technologies, with the learning and development programs that are conveyed on a computer in achieving both the learning and organizational goals [1].

For the company, E-learning has been proven as an integral part in the success of the company which enable people to connect themselves with other team members and create a meaningful relationship with the company itself, beyond time and distance. MAP invested in their people as their most important resources through the development of a robust Learning Management System (LMS), partnering with an international company specializing in learning technology. During this global pandemic caused by the spread of Covid-19 virus, LMS was one of the effective tool for communication and even the campaign on the new normal habits. The Management was able to reach all of the employees spread across Indonesia and few other countries such as Thailand, Vietnam and Philippine. Socialization on the new business strategies were also done through the system.

\section{Industry 4.0 and Retail Industry}

With this current ever-changing era in Industry 4.0, the growth of advancing information technology systems forced industries to not only adjusting their business process but also to transform the processes. The concept of Industry 4.0 came from Germany and was presented during Hannover fair in the year 2011. The ultimate concept is to utilize the capacities of new technologies and concepts such as [2]:

- Accessibility and utilization the internet or the Internet of Things (IoT)

- Industry technical and business processes integration

- Real world digital planning and mapping and virtualization

- 'Smart' factory, 'smart' industrial production and 'smart' products.

All the implementations trust will help companies expanding in a faster timeline and at lower cost. In

E-Learning Utilization and the Impact for People Development in Retail Company 
Industry 4.0, all the advance technology will make business to be able to fully integrated across functions and will make company gain position and available to take on the challenges on the journey ahead.

Retail industry considered as one that is greatly affected by the industrial revolution 4.0. The movement of people purchasing online rather than through the brick and mortar stores has become a very big challenge for retail business that only relies on traditional shop operating retails. Aside from those signal, the impact of Industry $4.0 \mathrm{in}$ retail industry also marked by an array of computerization and IT advances. This also become a moment for massive changes where credit cards usages emerged, back-office processes and warehouse automation, just-in- time supply chains and online business models are the trends. According to Price Waterhouse Coopers (PWC), Industry 4.0 will transform retail and consumer goods in so many significant aspects. Multichannel offerings or often times called as $\mathrm{O} 2 \mathrm{O}$ concept (Online to Offline and Offline to Online) will involve advance real-time inventory management system and end-to- end transparency on product availability. Seamless channel integration will be affected by the suitable and cost-efficient distribution process, and real-time and live information and data utilization to perform analytical report will promote arrangement and allocation to the next level [3].

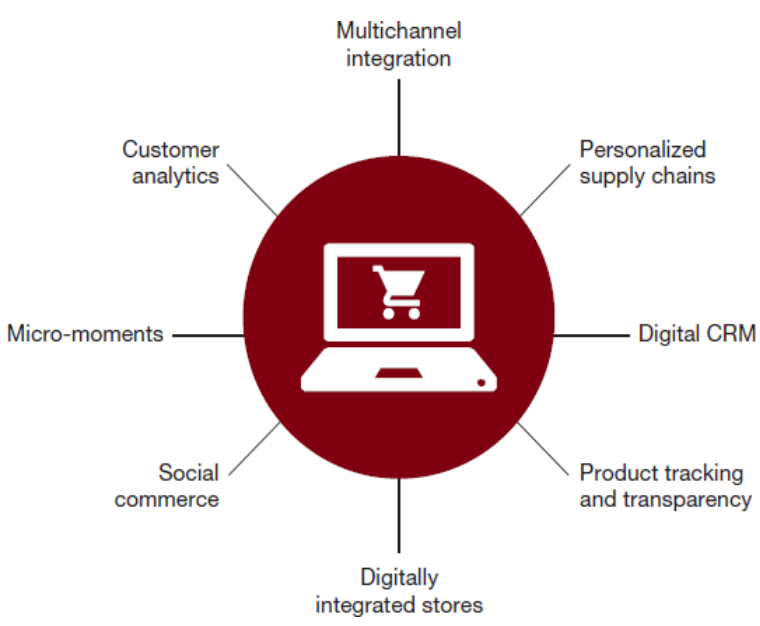

Figure 1. Retail and Consumer Goods Companies Increasingly Turn to Industry 4.0 ("Strategy and, Industry 4.0 Opportunities and Challenges for Customer Products and Retail Companies, PWC, 2016)

However, successful retailers will view this transformative period as a great chance and possibility to grow their business, their revenue and profits and getting ready for redesigning their organizations for the next industrial revolution. To be able to do this, retail companies will need to be supported by competent and skilful employees in their workforce.

\section{E-Learning and Learning Management System}

The usage E-learning by corporates is currently mounting as many companies have adopted E- learning in providing training and development for the employees in order to create a collaborative learning environment. Through E-learning, companies basically are able to train employees' skills and ability, extend services and propagate the company's policies [4]. However e-learning comprises much more than just online learning, it is about how we are interacting virtually through different networks. E-learning can be differentiated into some categories, which are fully online, blended, or hybrid combining brick and mortar learning and virtual programs. Different format of E-Learning might include instructor-led group, self-study, and self-study involving subject matter expert, web based program, computer based program, and video/audio tapes. Not only that, E-Learning can also be delivered using printing materials such as e-text, eBooks, e-zines, video (streaming or recorded), audio (streaming, recorded, or through podcast), reviews and exams (electronic, interactive evaluation), and also asynchronous communication (guided and specific topic discussions, forums) or synchronous type of communication (videoconference and teleconference) [1].

E-Learning not only considered as an effective and efficient, but also enables organization to provide training and development program consistently to all employees, to lessen traveling cost to outside training facilities as well as to provide training to employees at anytime and anywhere. Aside from training and development program, organizations often times also utilize E-Learning as their communication and operational support tool. With all the benefits, E-Learning has also been considered as costeffective though companies might require big investment for developing a comprehensive Learning Management System.

Earlier in this millennium, online education and training have been considered as the competitor for brick and mortar sessions. The limitation for classroom-based programs are the dependency on textbook, therefore many teachers and learning professionals have started viewing internet not just providing information nonetheless as a learning and training tool. Utilizing internet as a medium can be attributed to the growth and availability of Learning Management System (LMS). LMS is defined as learner and organization focus concerning on the logistics of learners management, mapping the competency of the organization, including developing the learning activities. LMS will also assess and evaluate learner's current level of knowledge and, identify and set the learning sequence required by the learner, store the evidence of attainments and to generate reports that will help in measuring the effectiveness of the entire learning process in the organization [5].

Commonly, LMS provides wide range of functionalities and instruments in supporting training and learning process. For an organization LMS enable collaborative and interactive learning process, also blended learning with all depending on the effectiveness of the information integration and communication technologies used in the 
e-learning. Content inside the LMS affected by four most important factors [5]:

\section{- Organizational Goals and Objectives}

E-learning in an organization should fulfill short and long term objectives of an organization and this should be budgeted in the organizations budgetary

\section{- Technical Specifications and Support} Choosing any LMS for an organization should also considering the system that is currently being used to ensure its compatibility, and it also should be effortless installing and operating, also offers possibility of mobile access

\section{- LMS Design and Functionalities}

The design specifications and functionalities also play an important part in choosing an LMS. Ensuring that it has clear and user friendly graphical interface, well designed course repository, has the capability for among users interaction, and providing evaluation and feedback are crucial.

\section{- Pedagogical Support Provided by an LMS}

The recommended pedagogical approaches in this online learning concept is constructivist approach. Here learners develop their knowledge through applying their current and existing knowledge (also known as tacit knowledge) to the new real situation and thus learning the new things will taking place. In the learning journey as we are talking about adult learning process, andragogy approach will need to be incorporated as well. One of the method is including MOOC or massive open online courses such as from Google, Facebook, Academia and many more in the platform which can also be cost friendly alternative for an organization in designing their learning platform.

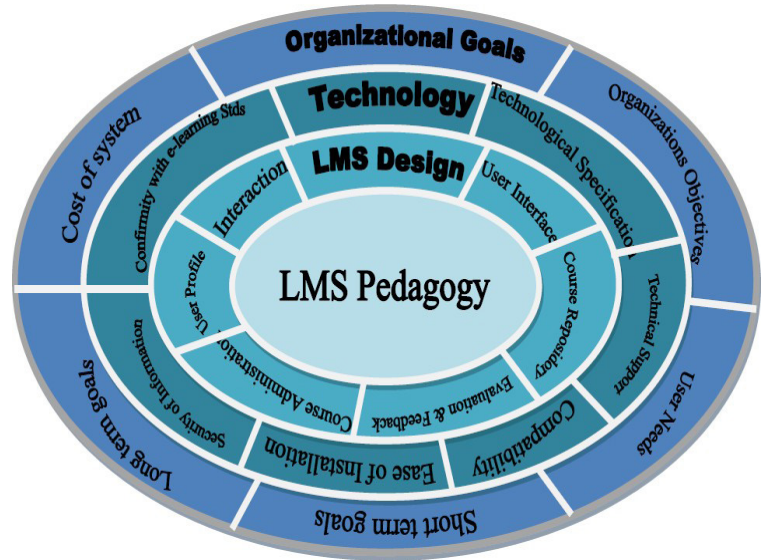

Figure 2. Cross Sectional View of an LMS (Learning Management Systems (LMS): Inside Matters, 2011)

This disruptive era has produced a very vulnerable condition where the adaptability of an organization plays a crucial role in the sustainability of the business. One of the key success factor for this is the ability of its human resources to learn new things and mastering the new skills required also in a fast pace. E-learning and the LMS as the platform could be a solution for organizations to be able to win the competition.

\section{METHOD}

This paper was prepared through a systematic literature review and gathering source of information in the internet related to the problem discussed which in this case related to the E- learning and LMS application for companies or organization for later analysis. The main purpose of this paper is to obtain relevant information and to understand the connectivity of each information with one and another.

1. Gather sources of information and existing literature from the internet, own experiences, and other materials related to this topic

2. Gathering information from the subject matter experts related to the topics that will be discussed related to this topic

3. Reading the sources that have been obtained

4. Identify the information read to identify the relevancy to the topics will be discussed,

5. Summarizing the key points from each relevant literature

6. Write down and rearrange the important points that have been collected in a structured manner for this paper

\section{RESULT AND DISCUSSION}

PT XYZ. (MAP) is Indonesia's largest lifestyle retail company that was incorporated in 1995 . With over 2,500 retail stores presence in 81 cities in Indonesia and few neighboring countries (Thailand, Vietnam, and Philippines), MAP was voted as Top 20 Most Admired Companies by Fortune Indonesia for few times and listed as Top 40 Companies by Forbes Indonesia. MAP has a diversified portfolio that includes sports, fashion, kids, food \& beverage, department store and lifestyle products, with some iconic brands such as Starbucks, Zara, Marks \& Spencer, SOGO, Seibu, Reebok, Converse, among many others. Achievements that were obtained mainly because of their people or employees topped with strong management team.

In their business philosophy, people placed at number one and this is the sign of how the company values their employees as an asset and the heart of the business. MAP committed to provide development for each of its employee as part of their growth with the company. The approach was really through brick and mortar or classroom sessions, where Learning Department under Corporate HR Division will invite people to the Head Quarter to participate in their programs. While for outstation and international branches, assigned trainers will do a regular visit and hold training programs in designated city for each region. The company also identified the extended hands of Learning Department by building pool of talent of Training Coaches that will help in delivering regular training sessions and monitoring the implementation. Such approach has cost the company huge investment mainly on the number of learning professionals in the 
organization, the establishment of their learning facilities and not to mention the traveling expenses. I

\section{We are a P.E.O.P.L.E Oriented Company \\ P eople Centered Approach}

\section{E mpowerment}

O riginality

$P$ rinciples

L oyalty

\section{E arnings}

Figure 3. MAP People Philosophy (https://www.map.co.id/ about-us/) Learning Management System (LMS) in MAP

With the company's growth and business expansion, the needs of a strong and competent employees extremely felt by the company especially on the Operation function as the core of the business. Retail trends have also been shifted for the past few years and this also urging the employees to adapting and learn quickly on the information and skills required. Those are the consideration for the company to establish a robust Learning Management System in order to provide just-in-time training programs for their employees.

Entering 2014 MAP revamped their learning and development to play a more strategic role in the company's business by introducing a new Learning Management System. Piloting to their 2 biggest food \& beverage brands, MAP launched their LMS called iMAP in partnership with a vendor from Australia. The main purpose of this LMS is really to serve the short and long term objectives of the company where employees are the integral part of the journey.

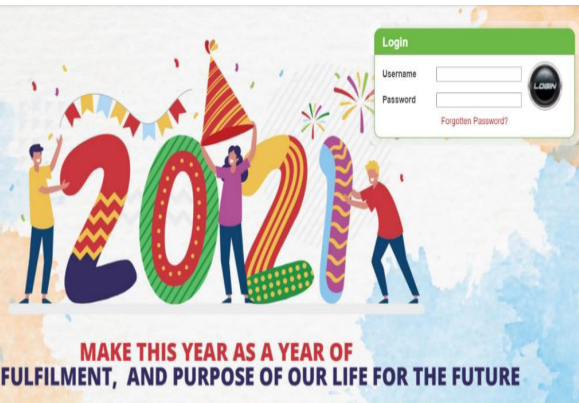

Figure 4. Display of MAP Learning Management System (iMAP)

\section{homepage}

iMAP enables each brand or Business Unit in the company to has their own landing page and this has create a different journey and experience for the employees aligned with the learning journey designed for each brand.
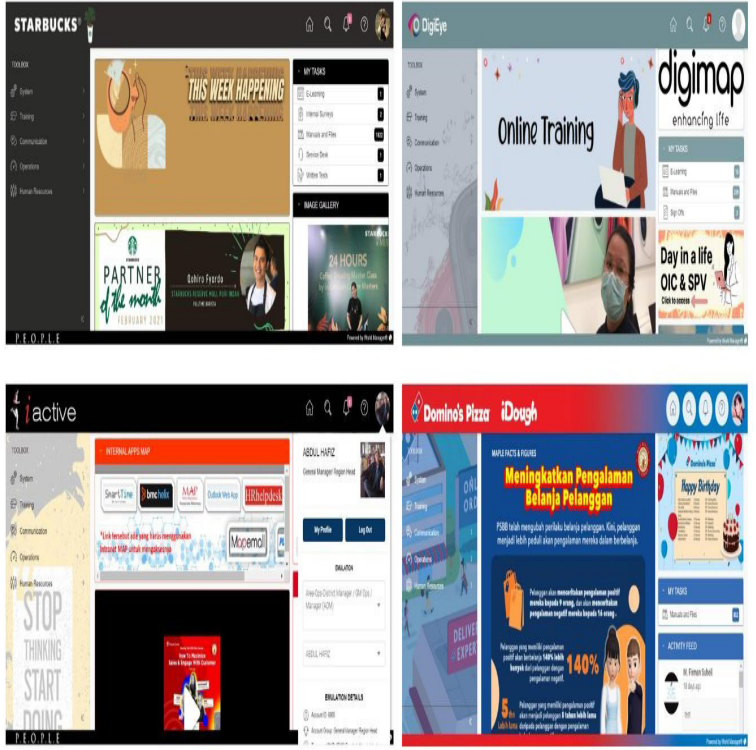

Figure 5. Display of different landing page in iMAP for different brands (https://imap.worldmanager.com)

The system has 4 key features available to support a comprehensive journey and experience with the platform.

\section{- Training Suite}

Is where employees are able to see all learning and development programs dedicated for them according to their employment level and role in their specific brand or Business Unit. In this Training Suite, files, videos, audios, even interactive content and link to access external MOOC are provided for employees.

iMAP has also enable the company to provide different learning experience such as gamification where employees are able to learn while they are playing a game that was specifically designed to hit certain skills and competencies. Gamification itself is still in relation but not identical with the model of game-based learning, it's referring to the usage of game design components in a non-game framework or situation. This game- based learning referring to the usage of real and actual game to acquire the skills, knowledge and competencies [6].

Through Training Suite, employees are able to learn all the required competencies at any time and from anywhere, even they can access the contents through their mobile phone.

\section{- Communication Suite}

This suite enable employees to be connected with other employees through Forum discussion. Company administrator can design a specific discussion topic and employees can share their thought and comments in each specific room.

Other than that, company can also communicate any information or even share messages from the Management team to all employees across provinces in Indonesia even in the International locations. During the hardship of Covid-19 pandemic, MAP Leadership and Management team regularly communicating and sending motivational messages through the platform. This is proven as an effective way to show support to the employees and this 
bring the Employee Engagement Survey score for 2020 at an average of 4.37 for overall company out of 5.0.

\section{- Operations Suite}

This suite is the uniqueness of iMAP, where employees are also able to utilize the platform for Operational checklist (such as store opening and closing checklist), Operational audit form, including service desk to report any repair and maintenance needs from the store.

Through this feature, MAP as a company has been able to centralize all the SOPs and other company regulations to be accessible at all time by the employees.

\section{- Human Resources Suite}

Here is where employees are able to download and submit all HR related forms, from medical reimbursement, employee data update, until exit interview forms. This suite also facilitate the employee surveys organized by the company.

\section{Comprehensive E-Learning Program}

Implementing Learning Management System will require a comprehensive design of the learning program which align with the competency required for each position or level in the company. E-learning provides greater amounts of control to each of the participants on their own learning progress. In this self-paced learning process, learning structure is crucial to be designed and created as it is expected to be able to have a positive relationship with job productivity, job performance, job satisfaction and organizational commitment.

The company has designed a structured and competency based learning programs for each level in the company called MAP Learning Pathway. Consists of all mandatory learning materials that need to be completed by all employees before they can enjoy other development programs open for them. The main purpose of this program is to ensure that all employees in the company understand their role in the company in order for them to be able to contribute their best for the success of the company. MAP Learning Pathway was designed with a combination of cognitive learning and implementing Bloom's taxonomy pyramid to ensure maximum impact and implementation. Cognitive learning is where we are supporting the learning points to be stored in the Long-Term Memory by activating the senses of the participants, therefore learning contents will combine hearing (through audio, video, and other sounds) with visual contents (reading, video, graphics or pictures). Often times also engaging the kinesthetic side of the participants through games and quizzes. Content wise, also referring to Bloom's taxonomy as the basis in creating Active Training where facilitators will help to enable the participants to construct their understanding, teaching them to proactively become a problem solver and critical thinker. Meaning, all programs and contents created will always be participants centered where they are required to gather, analyze and evaluate all information provided independently [8].

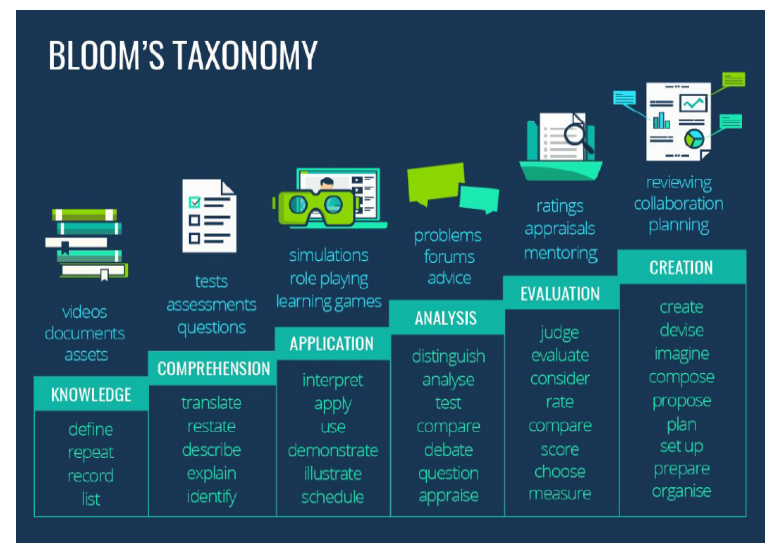

Figure 6. Bloom's Taxonomy steps (Cognitive Development in Active eLearning, 2018)

Aside from this MAP Learning Pathway, the company has also created other development programs, combining soft competencies such as communication, leadership and personal development, with other technical skills such as Microsoft Office and English programs. However, the company also listening to the feedback given from the employees to ensure effectiveness of the learning program. Therefore MAP has implemented Blended or Hybrid program as the solution. Hybrid learning model refers to the blending of learning environments, which are face-to-face classroom session and online environment. As the technology advancement, the face-to-face classroom session nowadays can be accommodated through a concept of distance learning which offers development program beyond the limitation of space and time. In the practice, MAP Learning and Development team adopting the four properties of Hybrid Learning [7]:

- Combination of collective and individual learning

- Combination of synchronous (virtual classroom sessions) and asynchronous learning

- A combination of self-paced and group-paced learning

- A combination of formal and non-formal learning in providing the lifelong and continuous learning

The application of the above properties have recorded a total of 458,364 learning hours in 2020, close to $40 \%$ higher compared from 2019 at 284,185 learning hours. This is definitely will not be possible to be achieved with the conventional training approach and considered as a more cost effective approach as well.

The Management believes that even the sales achievement of the company is the result of this E-Learning implementation. MAP is supported by their best talents who keep themselves updated and at par with the current standard and trends.

\section{CONCLUSION}

Industry 4.0 and the VUCA era, has forced retail companies to set strategies in adapting with the rapid changes. Being adaptable, agile and resilient is important to survive in the competition. This requires the human resources inside the 
industry to also being prepared and getting ready for the turmoil. Utilizing E-Learning and Learning Management System is the backbone to be able to provide real time development program for the employees beyond places and time. With a well-designed E-Learning program, retail companies and companies form other sectors in general will be able to stay in the market. PT XYZ. (MAP) managed to transform their learning culture to the digital learning model through E-Learning and Learning Management System implementations. Employees across Indonesia and in 3 other countries where the business is located have all the competencies required for them to perform at their best aligning with the current trends. They are also always in the loop of any updates or messages from the company. Hence MAP is able to stay as the leading retail company in Indonesia.

\section{REFERENCES}

[1] K. D. Kuznia, "Corporate Elearning Impact on Employees," Global Journal of Business Research, vol. 8, no. 4, pp. 1 - 16, 2014

[2] A. Rojko, "Industry 4.0 Concept: Background and Overview," International Journal of Interactive Mobile Technologies, vol. 11, no. 5, pp. 77 - 90, 2017
[3] Strategy and 2016, Industry 4.0 Opportunities and Challenges for Customer Products and Retail Companies, Price Waterhouse Coopers, accessed on March 20, 2021,

[4] W. T. Cheng, C. Chen, "The Impact of E-Learning on Workplace On-the-job Training," International Journal of E-education, E-Business, E-Management and E-Learning, vol. 5, no. 4, pp. 212 -228, 2015

[5] S. Iqbal, I. A. Qureshi, "Learning Management System (LMS): Inside Matter," Information Management and Business Review, vol. 3, no. 4, pp. 206-216, 2011

[6] K. Welbers, E. A. Konijn, C. Burgers, A. B. de Vaate, "Gamification As a Tool for Engaging Students Learning: A Field Experiment With a Gamified App," E-Learning and Digital Media, vol. 16, no. 2, pp. $92-109,2019$

[7] S. M. AlNajdi, (2014, March). "Hybrid Learning in Higher Education": Indiana State University [Proceeding]. Society for Information Technology \& Teacher Education 2014 International Conference, Jacksonville, Florida, United States.

[8] D. Ratniece, "Cognitive Development in Active eLearning," International Journal of Engineering and Technology, vol. 7, no. 2, pp. $53-57,2018$ 